\title{
Learning Styles and Their Relationship with Educational Performance of Medical Students in an Outcome Based Integrated Curriculum
}

\author{
Khwaja Mohammad Amir ${ }^{1}$, Nasser Ashraf Tadvi², Mohammad Rehan Asad ${ }^{3}$, \\ Riyaz Ahamed Shaik ${ }^{4}$, Abdul Irfan ${ }^{5}$, Nazim Nasir 6
}

\begin{abstract}
1, 3 Department of Basic Medical Science, College of Medicine, Majmaah University, Al Majmaah, Kingdom of Saudi Arabia. ${ }^{2}$ Department of Pharmacology, Ayaan Institute of Medical Sciences, Moinabad, Ranga Reddy District, Telangana, India. ${ }^{4}$ Department of Community Medicine and Public Health, College of Medicine, Majmaah University, Al Majmaah, Kingdom of Saudi Arabia. ${ }^{5}$ Department of Medical Education, College of Medicine, Majmaah University, Al Majmaah, Kingdom of Saudi Arabia. ${ }^{6}$ College of Applied Medical Sciences, King Khalid University, Abha, KSA.
\end{abstract}

\section{ABSTRACT}

\section{BACKGROUND}

Learning modality preference is one of various components of learning style. This study has been done among medical undergraduate students to explore their learning mode preference and its relation to academic performance.

\section{METHODS}

We studied learning style as Sensory Mode Preference (SMP) and preferred Teaching Learning Methodology (TLM) of $4^{\text {th }}$ semester undergraduate medical students ( $\mathrm{n}=$ 211; males $=168$, females $=43$ ) in Saudi Arabia. The validated VARK learning style questionnaire was used to determine SMP and standardized self-prepared questionnaire sheet was used to determine the most preferred TLM of students. We explored relationship between the determined sensory mode preferences of these students with their academic performance in the $2^{\text {nd }}$ semester.

\section{RESULTS}

Multimodal VARK (Visual + Auditory + Read - Write + Kinaesthetic) was the most preferred (25.5 \%) LMP. There was significant difference between perceived SMP of male and female students. Significant difference was also found between perceived and determined SMP of students. There was significant difference between male and female students for the most preferred TLM. There was no significant correlation between SMP and academic performance.

\section{CONCLUSIONS}

Multimodal LMP is more common than unimodal in this group of medical students. There is strong preference for TLM in which there is provision for different learning styles. Students are generally not aware of their own learning styles and so there should be investigation of learning style of each student and they should be encouraged to find out their learning styles. This will help them in learning and in enhancing their metacognition. In an integrated medical curriculum, which comprises of variety of active teaching learning methodologies, limitation of learning styles can be nullified.

\section{KEY WORDS}

Sensory Mode Preference (SMP), Teaching Learning Methodology (TLM), VARK, GPA
Corresponding Author: Dr. Riyaz Ahamed Shaik Department of Community Medicine and Public Health, College of Medicine, Majmaah University, Al Majmaah, 11952, Kingdom of Saudi Arabia.

E-mail: r.shaik@mu.edu.sa

DOI: $10.14260 /$ jemds $/ 2021 / 6$

How to Cite This Article: Amir KM, Tadvi NA, Asad MR, et al. Learning styles and their relationship with educational performance of medical students in an outcome based integrated curriculum. J Evolution Med Dent Sci 2021;10(01):28-33, DOI: $10.14260 /$ jemds $/ 2021 / 6$

Submission 20-08-2020, Peer Review 01-11-2020, Acceptance 09-11-2020, Published 04-01-2021.

Copyright (C) 2021 Khwaja Mohammad Amir et al. This is an open access article distributed under Creative Commons Attribution License [Attribution 4.0 International (CC BY 4.0)] 


\section{BACKGROUND}

Sensory learning modality preference is one of the various components of learning style which determines the person's ability to acquire new knowledge. It is one of the dimensions of the complex system of preferences that make up a person's learning style. ${ }^{1}$ Learning style is defined as the composite characteristic cognitive, affective and physiological characters that serve as relative stable indicators of how a learner perceives. $^{2,3}$ Sensory Mode Preference (SMP) refers to the physiological sensory modality in which people like information to come to them and the ways in which they like to deliver their communication.

There needs to be a constructive alignment of learning outcome, teaching methodology and assessment technique in order to have a successful curriculum planning. Hence it is very useful if the tutor is aware of the preferred learning mode of an individual student as well as predominant learning preference of the class. It has been observed that if the students receive instruction in their preferred learning mode they learn faster, known as meshing hypothesis. ${ }^{4}$

To cope with medical curriculum each student adopts certain style to internalize the knowledge content. There are various ways to describe these learning styles but one of the most popular and practical way is the use of sensory modality which the student utilizes in learning. Bruner (1967) and Piaget (1990) found four different sensory modalities that are used by humans to assimilate information, these are visual, auditory, reading / writing and kinaesthetic (VARK). ${ }^{1,5}$ Based on this concept, Neil Fleming developed an online questionnaire to classify the learning styles based on these learning style. ${ }^{2}$ Fleming further mentions that the analysis of this questionnaire just gives us the preferred learning modality and not the complete learning style. The term learning style in literature is so much used in place of mode of learning that they may be considered same for all practical purposes.

Studies have demonstrated that if the information is delivered to the students using the preferred learning modality of the students, the teachers are able to connect better to the students as well as their learning is enhanced. ${ }^{6-12}$ One of those important strategies for teacher to improve their communication with their students is to adopt multiple learning modalities in their instructional methodology, there are numerous studies in support of this. ${ }^{9-14}$

Many of the studies done for learning style assessment have also tried to find correlation between genders. Certain studies have found no significant difference in learning mode preference between male and female. ${ }^{15}$ On the other hand Slater et al (2007),16 reported a difference in learning mode preference of the two sexes. A study on German students found significant difference in learning style preference of male and female. ${ }^{17} \mathrm{Lu} \&$ Chiou (2010) conducted studies on learning style to see the difference in pattern of male and females. ${ }^{18}$ Paul et al (1994) in their study on medical students of United Arab Emirates found no significant difference in learning preference of male and female students. ${ }^{19}$

In college of medicine, Majmaah university an outcome based integrated curriculum is followed. Here we practice a number of teaching learning methodology, so we will try in our study to determine the sensory mode preference for learning of students so that that the teachers can utilize that knowledge to make their teaching more efficient. The TLM we follow here are interactive lectures, Problem Based Learning (PBL), clinical skill sessions, practicals, assignment writing etc. We are also going to find out that which teaching and learning methodology does each type of learner prefers the most. Our medical students are taught the learning styles in the module of Medical Learning Skills in their first semester, so in our study we will be asking them that what type of learner they presume themselves to be and later on we shall compare their perception about themselves with our results. Majmaah University also has a female college so we will compare the learning mode preference between male and female medical students of first year. The academic performance of the students here is reflected by the GPA (Grade Point Average) awarded at the end of each semester.

\section{METHODS}

A cross sectional descriptive study was done in 211 undergraduate students of College of Medicine, Majmaah University. All the students in different years of medical school were included in the study. Participants who didn't give consent for participation were excluded. Questionnaire was distributed among all 280 students. A total of 230 students responded and filled up the questionnaire and 19 students who didn't fill the questionnaire were excluded and the final sample size was 211 . The data was collected by the use of a 7.8 version of VARK questionnaire and a standardized selfprepared questionnaire were used as data collecting instruments.

The VARK questionnaire is used to assess the learning mode preference. It has been used for various studies for past many years. ${ }^{20}$ The purpose of this questionnaire is to determine the sensory learning mode preference in terms of Visual (V), Aural (A), Read / Write (R), Kinaesthetic (K) or a combination of these. This questionnaire consisted of 16 items and each item was followed by four options. The learning mode preference was analysed by steppingstone method.

A self-prepared item was given in separate sheet where subjects had to reflect their gender, level of course and their preference for teaching and learning methods arranged on five points liker scale starting from most preferred to least preferred. This college has an outcome based integrated curriculum. The teaching learning methodologies we gave in option were lecture, practical's, problem-based learning, clinical skills and assignments. They were also being asked to mention their self-perceived preferred mode of learning. The students were expected to perceive their preferred mode of learning because this concept was part of their syllabus in the 'Medical Leaning Skills' module given in the first semester in the college. The academic performance was assessed as the GPA in the second semester of each student. This GPA was obtained from the college administration with due permission.

\section{Data Analysis}

Descriptive statistics was used to analyse the obtained data. Relationships between different categorical variables was studied using chi square test. GPA among students with different learning styles was compared using chi square test. $P$ 
value $<0.05$ was considered as significant. All analysis was done using SPSS software 20.0 version.

\section{Ethical Approval}

Prior ethical approval was taken from the Research Ethics Committee of College of Medicine, Majmaah University. Participation consent from the students was taken. They were also briefed about the advantages to them as well as to the student community due to their participation. The students were assured that all information will be kept purely confidential and will only be used for the purpose of research activity.

\section{RESULTS}

We included 211 students in the study out of which 181 responded of which 142 were males and 39 were females. Characteristics of the participants are given in Table 1. Most common SMP was VARK (51 \%) followed by K and A. However, most students perceived their LS to be VK or K. The most common perceived learning mode of male students was AK (Audio \& Kinaesthetic $=11.3 \%) \&$ VK (Visual \& Kinaesthetic $=$ $11.3 \%$ ) while that in females was $\mathrm{K}$ (Kinaesthetic $=28.2 \%$ ).

Thus males commonly perceived themselves as multimodal while females themselves as unimodal. By applying chi-square test, it was found that there was significant difference in perceived learning style of male and female students

\begin{tabular}{|c|c|c|c|c|c|c|c|}
\hline \multicolumn{8}{|c|}{$\begin{array}{l}\text { A. Perceived and Determined Learning Style } \\
\text { in Undergraduate Medical Students n (\%) }\end{array}$} \\
\hline & \multicolumn{3}{|c|}{ LS Perceived } & \multicolumn{4}{|c|}{ LS Determined } \\
\hline & Male & \multicolumn{2}{|c|}{ Female } & \multicolumn{2}{|c|}{ Male } & \multicolumn{2}{|c|}{ Female } \\
\hline A & $6(4.2)$ & \multicolumn{2}{|c|}{$1(2.6)$} & \multicolumn{2}{|c|}{$19(12.6)$} & \multicolumn{2}{|c|}{$8(21)$} \\
\hline $\mathrm{K}$ & $10(7)$ & \multicolumn{2}{|c|}{$11(28.2)$} & \multicolumn{2}{|c|}{$29(19.2)$} & \multicolumn{2}{|c|}{$6(15.8)$} \\
\hline $\mathrm{AK}$ & $16(11.3)$ & \multicolumn{2}{|c|}{$4(10.3)$} & \multicolumn{2}{|c|}{$19(12.6)$} & \multicolumn{2}{|c|}{$0(0)$} \\
\hline VK & $16(11.3)$ & \multicolumn{2}{|c|}{$8(20.5)$} & \multicolumn{2}{|c|}{$6(4)$} & \multicolumn{2}{|c|}{$4(10.5)$} \\
\hline VARK & $6(4.2)$ & \multicolumn{2}{|c|}{$2(5.1)$} & \multicolumn{2}{|c|}{$40(26.5)$} & \multicolumn{2}{|c|}{$11(28.9)$} \\
\hline Others & $88(62)$ & \multicolumn{2}{|c|}{13 (33.3) } & \multicolumn{2}{|c|}{38 (25.1) } & \multicolumn{2}{|c|}{$9(23.7)$} \\
\hline \multicolumn{8}{|c|}{$\begin{array}{l}\text { B. Correlation between Perceived and Determined } \\
\text { Learning Styles of Students }\end{array}$} \\
\hline \multicolumn{2}{|c|}{ LS PERCEIVED } & A & $\mathrm{K}$ & $\mathrm{AK}$ & VK & VARK & Others \\
\hline \multirow{6}{*}{$\begin{array}{c}\text { LS } \\
\text { Determined }\end{array}$} & A & 1 & 2 & 2 & 3 & 0 & 16 \\
\hline & $\mathrm{K}$ & 1 & 5 & 8 & 5 & 0 & 15 \\
\hline & $\mathrm{AK}$ & 0 & 3 & 3 & 2 & 1 & 8 \\
\hline & VK & 0 & 3 & 0 & 2 & 0 & 5 \\
\hline & VARK & 2 & 3 & 4 & 5 & 3 & 30 \\
\hline & Others & 3 & 3 & 2 & 7 & 4 & 25 \\
\hline \multicolumn{2}{|c|}{ Total } & 7 & 19 & 19 & 24 & 8 & 99 \\
\hline \multicolumn{8}{|c|}{$\begin{array}{l}\text { Table 1. Distribution of Medical Students Based on } \\
\text { Learning Styles and Their Correlation }\end{array}$} \\
\hline
\end{tabular}

Significant difference $\mathrm{p}-0.003$ was found in the perceived learning style in between males and female. Significant difference between perceived and determined learning style was found $p=0.001$ by chi square test. There was found to be significant difference in perceived and determined learning styles. When determined by VARK stepping stone method majority of males as well as females where quadrimodal (VARK) $26.5 \%$ and $28.9 \%$ respectively. In the unimodal kinaesthetic (19.2\%) was the commonest in the males while auditory ( $21 \%$ ) was commonest in females. Thus, we see that there is domination of audio and kinaesthetic mode of learning. Perception of $11.9 \%$ of males completely matched their LS, while this number was only $9 \%$ in case of females. $14.5 \%$ of males and $15 \%$ of females completely failed in perceiving their LS. (Table 1).

Most preferred TLM was CS (29.4\%) followed by Lecture and PBL. Assignment was the least preferred TLM by majority of students (71.9\%). Most preferred TLM was PBL and clinical skills in males and females respectively. Assignment writing was least preferred by both the genders.

\begin{tabular}{|c|c|c|c|c|c|c|c|c|}
\hline & & $\mathbf{A}$ & $\mathbf{K}$ & AK & VK & VARK & Others & Total \\
\hline \multirow{3}{*}{ Male } & Count & 6 & 10 & 16 & 16 & 6 & 88 & 142 \\
\hline & $\begin{array}{l}\% \text { within } \\
\text { gender }\end{array}$ & $4.2 \%$ & $7.0 \%$ & $11.3 \%$ & $11.3 \% *$ & $4.2 \%$ & $62.0 \% *$ & $100.0 \%$ \\
\hline & $\%$ of Total & $3.3 \%$ & $5.5 \%$ & $8.8 \%$ & $8.8 \%$ & $3.3 \%$ & $48.6 \%$ & $78.5 \%$ \\
\hline \multirow{3}{*}{ Female } & Count & 1 & 11 & 4 & 8 & 2 & 13 & 39 \\
\hline & $\begin{array}{l}\% \text { within } \\
\text { gender }\end{array}$ & $2.6 \%$ & $28.2 \% *$ & $10.3 \%$ & $20.5 \%$ & $5.1 \%$ & $33.3 \%$ & $100.0 \%$ \\
\hline & $\%$ of Total & $0.6 \%$ & $6.1 \%$ & $2.2 \%$ & $4.4 \%$ & $1.1 \%$ & $7.2 \%$ & $21.5 \%$ \\
\hline \multirow{3}{*}{ Total } & Count & 7 & 21 & 20 & 24 & 8 & 101 & 181 \\
\hline & $\begin{array}{l}\% \text { within } \\
\text { gender }\end{array}$ & $3.9 \%$ & $11.6 \%$ & $11.0 \%$ & $13.3 \%$ & $55.8 \%$ & $55.8 \%$ & $100.0 \%$ \\
\hline & $\%$ of Total & $3.9 \%$ & $11.6 \%$ & $11.0 \%$ & $13.3 \%$ & $55.8 \%$ & $55.8 \%$ & $100.0 \%$ \\
\hline \multicolumn{9}{|c|}{${ }^{*} \mathrm{P}<0.005$} \\
\hline \multicolumn{9}{|c|}{ Table 2. Perceived Learning Styles of Students } \\
\hline
\end{tabular}

\begin{tabular}{|c|c|c|c|c|c|c|}
\hline \multirow[b]{2}{*}{ Gender } & & \multicolumn{5}{|c|}{ Most Preferred TLM } \\
\hline & & Lecture & Practical & PBL & CS & Assignment \\
\hline \multirow{3}{*}{ Male } & Count & 47 & 9 & 49 & 43 & 3 \\
\hline & $\begin{array}{l}\% \text { within } \\
\text { gender }\end{array}$ & $31.1 \%$ & $6.0 \%$ & $\begin{array}{c}32.5 \\
\% *\end{array}$ & $28.5 \%$ & $2.0 \%$ \\
\hline & $\%$ of Total & $24.7 \%$ & $4.7 \%$ & $25.8 \%$ & $22.6 \%$ & $1.6 \%$ \\
\hline \multirow{3}{*}{ Female } & Count & 10 & 8 & 2 & 19 & 0 \\
\hline & $\begin{array}{l}\% \text { within } \\
\text { gender }\end{array}$ & $25.6 \%$ & $20.5 \%$ & $5.1 \%$ & $\begin{array}{l}48.7 \\
\% *\end{array}$ & $0.0 \%$ \\
\hline & $\%$ of Total & $5.3 \%$ & $4.2 \%$ & $1.1 \%$ & $10.0 \%$ & $0.0 \%$ \\
\hline \multirow{3}{*}{ Total } & Count & 57 & 17 & 51 & 62 & 3 \\
\hline & $\begin{array}{l}\% \text { within } \\
\text { gender }\end{array}$ & $30.0 \%$ & $8.9 \%$ & $26.8 \%$ & $32.6 \%$ & $1.6 \%$ \\
\hline & $\%$ of Total & $30.0 \%$ & $8.9 \%$ & $26.8 \%$ & $32.6 \%$ & $1.6 \%$ \\
\hline \multicolumn{7}{|l|}{${ }^{*} \mathrm{P}<0.001$} \\
\hline Table & istribut & n of Mo & Preferred & $d T L M$ & with $G$ & ender \\
\hline
\end{tabular}

\begin{tabular}{|ccccc|}
\hline & Vark & Kinaesthetic & Auditory & AK \\
L & 10 & 12 & 13 & 4 \\
P & 5 & 3 & 3 & 1 \\
PBL & 19 & 9 & 2 & 7 \\
CS & 17 & 10 & 7 & 7 \\
A & 0 & 0 & 0 & 0 \\
SMP - TLM & \multicolumn{5}{c|}{ Table 4. Preferred Teaching Learning Method for } \\
\hline \multicolumn{5}{c}{ Students of Different Learning Styles } \\
\end{tabular}

\begin{tabular}{|ccc|}
\hline & GPA $>\mathbf{4}$ \% & GPA $<\mathbf{3} \%$ \\
V & 16.7 & 16.7 \\
A & 30.0 & 20.0 \\
R & 66.7 & 33.3 \\
K & 18.2 & 15.2 \\
VA & 100.0 & 0.0 \\
VR & 0.0 & 0.0 \\
VK & 22.2 & 44.4 \\
AR & 0.0 & 0.0 \\
AK & 27.8 & 22.2 \\
RK & 100.0 & 0.0 \\
VAR & 0.0 & 0.0 \\
VAK & 25.0 & 18.8 \\
VRK & 50.0 & 0.0 \\
ARK & 0.0 & 55.6 \\
VARK & 40.0 & 22.2 \\
\hline Table 5. Academic Performance of Different Learning Styles \\
\hline
\end{tabular}


No significant difference was found between SMP of male and female students $(p=0.107)$. However, perceived SMP were significantly different between males and females $(p=$ 0.002). Most males perceived their SMP to be AK, VK or others whereas majority of females perceived their SMP to be $\mathrm{K}$ or others (Table 2). However, most preferred TLM differed significantly between males and females $(p<0.001)$. Majority of male students preferred PBL or lecture whereas females had a greater preference for CS. PBL was the most preferred TLM for only $5.1 \%$ of all females. No significant relationship was found between gender and least preferred TLM ( $p=$ 0.359 ) and assignment was the least preferred TLM for majority (74.3\%) of students (Table 3 ).

As very much expected clinical skills is most preferred by the VARK learners. A very interesting finding is that unimodal auditory and kinaesthetic learners have maximum preferences for lectures. (Table 4)

It was found that there was no significant association of academic achievement with different learning styles. The quadrimodal learning style VARK was associated with $42 \%$ of high achievers ( $>4 \mathrm{GPA}$ ) and $22 \%$ of low achievers ( $<3 \mathrm{GPA})$. Unimodal learning styles was associated with $31 \%$ of high achievers and $21 \%$ of low achievers. (Table 5)

\section{DISCUSSION}

This study was unique because we took into consideration few of the very important parameters like the learning style, the teaching learning methodology and the academic performance. Since this study was done in both the genders, it could differentiate the scenario in them. We also assessed the perceived and determined learning styles. In all the review done by us only two studies we could find which reported similar findings.3,21 Our study however holds the distinction of being higher in number of subjects than these two and first of such kind in Saudi Arabia. Our study is additionally taking up the TLM preference as well into account.

\section{Difference between Perceived and Determined LS}

We found that majority of males perceived themselves to be bimodal (VK \& AK) while females perceived themselves as unimodal as Kinaesthetic (K). This difference between genders was found to be significant by the test. This is quite surprising in this traditional society of Saudi Arabia that females perceive themselves to be kinaesthetic learner. This point towards their attitude of learning by doing, which is a positive revelation.

When determined by VARK stepping stone method majority of males as well as females where quadrimodal (VARK) $26.5 \%$ and $28.9 \%$ respectively. In the unimodal, kinaesthetic (19.2\%) was the commonest in the males while auditory ( $21 \%$ ) was commonest in females followed by none else than kinaesthetic (15.8\%). This is quite contrary to their perception about themselves. Perception of $11.9 \%$ of males completely matched their SMP, while this number was only 9 $\%$ in case of females. $14.5 \%$ of males and $15 \%$ of females completely failed in perceiving their SMP. Hence males seem to have edge in metacognition. Conclusively this difference between perceived and determined learning style was found to be significant by the test. Thus, we see that there is domination of audio and kinaesthetic mode of learning in these students. Thus here we realize the importance of determining the true SMP of our students because there is a great probability that they have a false perception. Ojeh et al (2017) also found significant difference between perceived and determined SMP on the other hand Dobson (2010) in his study found that $59 \%$ of subjects had rightly perceived their SMP. 3,21

Finding similar to our findings on learning styles have been observed in many studies. Nuzhat et al (2013) did a study of learning style in medical students and found almost similar result that dominant learning style was multimodal while among unimodal kinaesthetic and aural were more. ${ }^{22}$ Abdallah et al (2013) found that nearly two third were multimodal while auditory was the dominant unimodal learning style in another study done in second year medical students of Saudi Arabia.23 Two other such studies done in first year medical students came out with the finding that multimodal learners outnumbered unimodal learners and kinaesthetic learning was most common unimodal learning preference. ${ }^{23}$, 24 Studies done in Nigeria, South America and India on learning preference of medical students came out with the similar finding that majority of learners being multimodal and kinaesthetic learning as the most preferred unimodal learning preference. ${ }^{26-28}$

\section{Difference between Perceived LS of Male and Female Students}

There was significant difference in the perceived SMP but not in the determined SMP of male and female students. Males commonly perceived their SMP as bimodal especially AK \&VK (11.3\% each) whereas the SMP scoring most for the female was kinaesthetic (28.2\%). Dobson (2010) found difference in the perceived SMP between genders but it did not reach to significant level. ${ }^{3}$

\section{LMP \& TLM - Predominance of CS in VARK and Lectures by $K \& A$}

The students with VARK mode preference had maximum preference for the clinical skill sessions as the most preferred teaching learning methodology. This finding is quite obvious as learning in these clinical skill sessions involve all these four sensory modalities. Although auditory learning is very much expected to go with lectures but presence of kinaesthetic is a surprise. This coincidence is because of the fact that our lectures are not didactic lectures rather they are interactive lectures. Each lecture has a PowerPoint presentation. The tutor in the lecture occasionally supplements the power point with interesting videos, short role play and occasionally brings real life specimens. These resources help to create real life like situations and even go up to stimulate kinaesthetic learning.

\section{No Significant Association of LS \& Academic Performance}

There was found to be no significant correlation with any of the SMP with the grades (GPA). As already stated in the results both unimodal and multimodal SMP had share of low and high grades. Many studies have showed similar results. A study conducted among Saudi medical students also found no significant association of grades with learning styles, although 
multimodal had higher grades compared to unimodal. ${ }^{22}$ Few studies in Saudi Arabia like that of Al Saud (2013) and Nazir et al (2018) show that multimodal learners achieve higher grades compared to unimodal learners. ${ }^{29,30}$

This result further emphasizes that our teaching methodologies in this integrated curriculum caters to different learning styles such that individual differences in learning style is neutralised. Here we can say that our integrated curriculum with various teaching learning methodologies caters to variety of learning styles such that the individual learning preferences are neutralized. Apart from the variety of TLM, each TLM emphasizes on active learning. This active learning brings into action most of the sensory modalities.

\section{Limitations}

VARK learning style is just a measure of most preferred sensory modality for learning. This study should be complemented with other learning style inventories like Kolbe \& Levin, Honey \& Mumford etc.

\section{CONCLUSIONS}

Majority of the students do not know their learning styles and there is high probability that the student has false perception of his SMP. It is recommended to determine and make record of the learning style of each student, if possible then with even variety of learning inventories. We can follow each student as we have recorded their particulars like university ID etc. and see that how the SMP changes with time. We can also correlate SMP with achievement of different types of exams like theory, OSPE, OSCE etc. There can be detailed qualitative study as an extension of this study like observing students, and interviewing teachers.

Data sharing statement provided by the authors is available with the full text of this article at jemds.com.

Financial or other competing interests: None.

Disclosure forms provided by the authors are available with the full text of this article at jemds.com.

The author would like to thank the deanship of research, Majmaah University for supporting this work.

\section{REFERENCES}

[1] Bruner JS. Toward a theory of instruction. Cambridge: Harvard University Press 1967.

[2] Flemming D. VARK. A Guide to Learning Styles. http://www.varklearn.com/english/page.asp?p_questionnaire

[3] Dobson JL. A comparison between learning style preferences and sex, status and course performance. Adv Physiol Educ 2010;34(4):197-204.

[4] Pashler H, McDaniel M, Rohrer D, et al. Learning styles: concepts and evidence. Psychol Sci Public Interest 2008;9(3):105-19.

[5] Piaget J. The child's conception of the world. New York: Littlefield Adams 1990.

[6] Alkhasawneh IM, Mrayyan MT, Docherty C, et al. Problembased learning (PBL): assessing students' learning preferences using vark. Nurse Educ Today 2008;28(5):572-9.

[7] Breckler J, Joun D, Ngo H. Learning styles of physiology students interested in the health professions. Adv Physiol Educ 2009;33(1):30-6.

[8] Meechan-Andrews TA. Teaching mode efficiency and learning preferences of first year nursing students. Nurse Educ Today 2009;29(1):24-32.

[9] Keller JM. Development and use of the ARCS model of instructional design. J Instr Develop 1987;10:2.

[10] Laight DW. Attitudes to concept maps as a teaching/learning activity in undergraduate heath professional education: influence of preferred learning style. Med Teach 2004;26(3):229-33.

[11] Miller JA. Enhancement of achievement and attitudes through individualized learning-style presentations of two allied health courses. J Allied Health 1998;27(3):1506.

[12] Tanner K, Allen D. Approaches to biology teaching and learning: learning styles and the problem of instructional selection-engaging all students in science courses. Cell Biol Educ 2004;3(4):197-201.

[13] Lujan HL, DiCarlo SE. Too much teaching, not enough learning: what is the solution? Adv Physiol Educ 2006;30(1):17-22.

[14] Wehrwein EA, Lujan HL, DiCarlo SE. Gender differences in learning style preferences among undergraduate physiology students. Adv Physiol Educ 2007;31(2):153-7.

[15] Philbin M, Meier E, Huffman S, et al. A survey of gender and learning styles. Sex Roles J Res 1995;32(7-8):485-94.

[16] Slater JA, Lujan HL, DiCarlo SE. Does gender influence learning style preferences of first-year medical students? Adv Physiol Educ 2007;31(4):336-42.

[17] Hlawaty H. Lernen and learning styles: a comparative analysis of the learning styles of German adolescents by age, gender, and academic achievement level. European Education 2008;40(4):23-45.

[18] Lu HP, Chiou MJ. The impact of individual differences on e-learning system satisfaction: a contingency approach. British Journal of Educational Technology 2010;41(2):307-23.

[19] Paul S, Bojanczyk M, Lanphear JH. Learning preferences of medical students. Med Educ 1994;28(3):180-6.

[20] Nuzhat A, Salem RO, Quadri MSA, et al. Learning style preferences of medical students: a single-institute experience from saudi arabia. Int J Med Educ 2011;2:703.

[21] Ojeh N, Sobers-Grannum N, Gaur U, et al. Learning style preferences: a study of pre-clinical medical students in Barbados. J Adv Med Educ Prof 2017:5(4):185-94.

[22] Nuzhat A, Salem RO, Al Hamdan N, et al. Gender differences in learning styles and academic performance of medical students in Saudi Arabia. Med Teach 2013;35(Suppl 1):S78-82.

[23] Abdallah AR, Al-Zalabani A, Alqabshawi R. Preferred learning styles among prospective research methodology course students at Taibah University, Saudi Arabia. J Egypt Public Health Assoc 2013;88(1):3-7.

[24] Baykan Z, Naçar M. Learning styles of first-year medical students attending Erciyes University in Kayseri Turkey. Adv Physiol Educ 2007;31(2):158-60. 
[25] Lujan HL, DiCarlo SE. First-year medical students prefer multiple learning styles. Adv Physiol Educ 2006;30(1):1316.

[26] Ubah JN. Learning styles among medical students, a case study of Ladoke Akintola University of Technology Medical School, Osogbo, Western Nigeria. J Educ Pract 2012;3(5):47-51.

[27] Ramirez BU. The sensory modality used for learning affects grades. Adv Physiol Educ 2011;35(3):270-4.

[28] Choudhary R, Dullo P, Tendon RV. Gender differences in learning style preferences of first year medical students. Pak J Physiol 2011;7(2):42-5.
[29] Nazir MA, Al-Ansari A, Farooqi FA. Influence of gender, class year, academic performance and paternal socioeconomic status on learning style preferences among dental students. Journal of Clinical and Diagnostic Research 2018;12(6):ZC04-8.

[30] Al-Saud LMS. Learning style preferences of first-year dental students at king saud university in Riyadh, Saudi Arabia: influence of gender and GPA. J Dent Educ. 2013;77(10):1371-8. 